\title{
O REFLEXO DA VISITA DOMICUIIAR DO ACS NA BUSCA ATIVA DO SR DE UM MUNIGIPIO DA AMAZÔNIA
}

\author{
Effeet of the Community Health Agent home visit in the active sereening for RS in an Amazonian munieipality
}

\author{
Camilo Eduardo Almeida Pereira ${ }^{1}$, Marcos Valério Santos da Silva ${ }^{2}$, \\ Mary Elizabeth de Santana ${ }^{3}$, Danyelle Rodrigues Kobayashi ${ }^{4}$, Laura Maria Vidal Nogueira ${ }^{5}$
}

\section{RESUMO}

Este estudo tem como objetivo avaliar a qualidade da visita domiciliar dos agentes comunitários de saúde, a fim de compreender a importância deste ator na busca ativa do sintomático respiratório. A investigação seguiu a trajetória descritiva, adotando um estudo de abordagem qualitativa. Participaram do estudo 12 agentes do Município de Belém. Pode-se aferir que o conhecimento dos agentes sobre a busca do sintomático respiratório é limitado, sendo que a visita deste profissional é focada no idoso portador de Doenças Crônicas Não Transmissíveis. A busca ativa não faz parte da rotina desses profissionais, além de não identificarem os grupos vulneráveis para tuberculose.

PALAVRAS-CHAVE: Agentes Comunitários de Saúde; Visita Domiciliar; Tuberculose.

\section{INTRODUÇÃO}

O Brasil atualmente vive uma acumulação epidemiológica, caracterizada pela persistência de doenças infectocontagiosas e desnutrição, e pela escala rápida das doenças crônicas não transmissíveis. Um dos fatores que contribui

\begin{abstract}
The objective of this study is to evaluate the quality of the home visit by community health agents, in order to understand the their importance in active screening for respiratory symptoms. The investigation followed a descriptive trajectory, adopting a qualitative approach. Twelve (12) agents from the Municipality of Belém participated in the study. It can be affirmed that the agents' knowledge about respiratory symptoms screening is limited, and that this professional's visit is focused on the elderly person with non-transmissible chronic diseases. Active screening is not part of the routine of these professionals, nor is identifying the vulnerable groups for tuberculosis.
\end{abstract}

KEYWORDS: Community Health Agents; Home Visit; Tuberculosis.

para essa polarização é que, no Brasil, ainda, anualmente, ocorre cerca de 4.700 óbitos devido à tuberculose (TB), doença curável e evitável. ${ }^{1,2}$

Esses dados ainda são preocupantes, porém vêm tendo uma melhora, ao longo dos anos, sendo que a criação do Programa Nacional do Controle da Tuberculose

\footnotetext{
1 Mestre. Professor Adjunto da Faculdade Pan Amazônica, ministrando a disciplina de Epidemiologia e preceptor da disciplina Doenças Crônicas Degenerativas pela Faculdade Integrada Brasil Amazônia. E-mail: camiloeduardo17@hotmail.com.

2 Doutor em Ciências Farmacêuticas pela Faculdade de Ciência Farmacêutica da USP/RP. Mestrado em Enfermagem em Saúde Pública pela Universidade de São Paulo, USP. Farmacêutico pela Universidade Federal do Pará. Professor Adjunto IV da Universidade Federal do Pará. Programa de Pós-Graduação do Mestrado Saúde, Ambiente e Sociedade na Amazônia da Universidade Federal do Pará.

3 Mestrado em Enfermagem Fundamental e Doutorado em Enfermagem Fundamental pela Escola de Enfermagem de Ribeirão Preto da Universidade de São Paulo (USP) e Pós-Doutorado pela Escola de Enfermagem de Ribeirão Preto da Universidade de São Paulo (USP). Professor Titular da Escola de Enfermagem Magalhães Barata da Universidade do Estado do Pará (UEPA) e Professor Associado I da Faculdade de Enfermagem da Universidade Federal do Pará (UFPA).

4 Graduada em Enfermagem pela Universidade do Estado do Pará. Enfermeira do Hospital Municipal de Castanhal.

5 Mestrado em Educação. Docência Universitária pelo Instituto Pedagógico Latino Americano e Caribenho - IPLAC - CUBA (2000) e Doutorado em Enfermagem pela Universidade Federal do Rio de Janeiro (2011). Professora Adjunta III da Universidade do Estado do Pará - Departamento de Enfermagem Comunitária. Coordenadora Geral do Programa de Pós-Graduação - Mestrado Acadêmico Associado UEPA/UFAM. Líder do Grupo de Estudos de Agravos em Populações Tradicionais da Amazônia.
} 
(PNCT) foi um dos fatores que impactaram positivamente nos indicadores brasileiros relacionados à $\mathrm{TB}$, pois o PNCT tem como objetivo "horizontalização" do combate à tuberculose, por meio da expansão de suas atividades para todos os serviços de saúde do Sistema Único de Saúde (SUS). Todos os planos nacionais e consensos para o controle da tuberculose, que se seguiram, enfatizaram a sua integração à atenção básica, utilizando-se a Estratégia Saúde da Família e, em específico, o Programa de Agentes Comunitários de Saúde (PACS), como forma de ampliar o acesso ao diagnóstico e ao tratamento da tuberculose em todo o Brasil. ${ }^{3}$

Os agentes comunitários de saúde (ACS), nesse contexto de ampliação do controle da tuberculose, têm um papel fundamental, porque dentre as atribuições desse profissional nesse processo incluem-se: realizar a busca ativa dos sintomáticos respiratórios (SR) nos domicílios e na comunidade, encaminhar ou comunicar o caso suspeito de TB à equipe; orientar a coleta e o encaminhamento do escarro dos SR; supervisionar a tomada diária da medicação específica, assegurar o comparecimento do doente às consultas agendadas e fazer visita domiciliar. ${ }^{4}$

Para Taddeo e colaboradores, ${ }^{5}$ o trabalho do ACS no controle da tuberculose é complexo, mas com grande potencial. Assim, esse profissional na atenção básica se constitui como uma peça fundamental, já que ele é o elo entre o serviço de saúde e a população, em que ambos somam forças para enfrentar os problemas de saúde e, especialmente, modificar as condições de vida. Por ele ter essa representatividade na comunidade, o mesmo teoricamente teria maior possibilidade de identificar o SR, culminando para um diagnóstico precoce e, consequentemente, um pronto tratamento, interrompendo a cadeia de transmissão da doença.

No entanto, para que haja êxito na busca ativa do SR, o ACS precisa incorporá-la durante as visitas domiciliares (VD), já que a VD possibilita o conhecimento da realidade das famílias acompanhadas, favorece a programação e o desenvolvimento das práticas de saúde. Dessa forma, a VD constitui o principal instrumento de trabalho dos ACSs, sendo que o Ministério da Saúde (MS) recomenda que haja no mínimo uma visita mensal, a cada domićlio da área de atuação do agente, havendo variações em função do estado de saúde de seus habitantes. ${ }^{6,4}$

O estudo de Jesus et al., realizado sobre atuação do ACS: conhecimento de usuários, teve como resultado que, apesar dos usuários evidenciarem a VD como instrumento de acompanhamento das famílias, estes depoimentos apresentaram algumas especificidades sobre o trabalho do ACS restrito às pessoas, que não podem deslocar-se à ESF, ao repasse de informações sobre a realização de exa- mes e ações direcionadas à saúde da criança. Tais respostas reafirmam uma visão biologicista, reduzindo as ações do ACS a ações tecnicistas e limitadas.

Esse modelo de VD limitada ao saber técnico precisa ser modificado, de maneira que a abordagem à família transcenda o saber biológico, principalmente, quando se trata da TB, doença que ainda tem uma representatividade negativa na sociedade. Dessa maneira, é necessário que o ACS seja capaz de caracterizar uma sequência de atividades que vão, desde o contato no domicílio à orientação sobre a doença, sinais e sintomas, modo de transmissão, identificação dos SR e orientação sobre a coleta de escarro. Dessa maneira, a qualidade da VD tem um impacto positivo no controle da tuberculose, pois não representa apenas a identificação do sintomático, mas um momento de troca de experiência com o usuário, família e comunidade, permitindo a participação social que terá um impacto na disseminação de informações sobre o processo de saúde- doença da tuberculose.

Diante desse panorama, este estudo tem como objetivo avaliar a qualidade da VD do ACS, a fim de compreender a importância desse ator para o controle da tuberculose, uma vez que se entende que o primeiro passo para um controle eficiente da TB é por meio da busca ativa do SR na comunidade, pois permite uma identificação precoce, interrompendo, assim, a cadeia de transmissão. E o ACS é fundamental nessa busca, já que a atuação desse profissional é especialmente na comunidade, por meio das VD mensais.

\section{MÉTODO}

O estudo faz parte da dissertação de mestrado do Programa de Pós-Graduação de Mestrado Saúde, Ambiente e Sociedade na Amazônia da Universidade Federal do Pará. Intitulado "O conhecimento dos Agentes Comunitários de Saúde do Município de Belém sobre a busca ativa do sintomático respiratório". A metodologia foi do tipo descritivo com abordagem qualitativa, com o foco nas VD prestadas pelos ACSs.

A escolha das ESFs e dos profissionais de saúde foi feita mediante a divisão do município, o qual está fragmentado em 8 distritos administrativos, no entanto, foram excluídos do estudo três distritos, uma vez que 2 distritos situavam-se na região das ilhas, precisando, assim, de uma melhor compreensão, além de uma infraestrutura para a realização das visitas, e outro distrito não apresentava ESFs, o que resultou em 4 distritos; porém, as ESFs que fizeram parte do estudo foram apenas de 3 distritos, uma vez que se conseguiu atingir o objetivo proposto. Assim, participaram do estudo 12 ACS do município de Belém, 
sendo três profissionais por ESF escolhida.

O estudo ocorreu no segundo semestre de 2016, sendo realizado com os ACSs, que assinaram o termo de consentimento livre esclarecido, previamente autorizado pelo parecer do Comitê de Ética do Instituto de Ciência e Saúde da Universidade Federal do Pará, sob o protocolo 1.834 .738 e autorizado pela Secretaria Municipal de Saúde, respeitando os princípios éticos, de acordo com resolução 466/12 (CNS/MS).

A coleta de dados foi realizada em dois momentos, o primeiro, por meio do acompanhamento do ACS, durante as visitas domiciliares, totalizando 57 visitas. Utilizou-se observação participativa com foco no tipo de abordagem que o ACS realizava na VD, bem como o tipo de orientação que o mesmo prestava à família, tendo como base atribuições e competências desse profissional, segundo a Política Nacional de Atenção Básica. Já no segundo momento, foi realizada uma entrevista semiestruturada que tivemos a preocupação de realizar, em local fechado, com presença apenas do pesquisador e do participante, a fim de manter o anonimato, utilizou-se o código alfanumérico, o qual foi composto da letra $\mathrm{E}$ de entrevista e o número sequencial. Adotou-se o uso de um roteiro prévio sobre a temática, gravando a entrevista em áudio e, posteriormente, realizadas as transcrições literais dos dados coletados. E a análise de dados foi feita por meio da análise de conteúdo proposta por Bardin. ${ }^{8}$

\section{RESULTADOS E DISCUSSÃO}

Quanto aos participantes do estudo, 9 eram do sexo feminino. Da mesma maneira, alguns estudos corroboram para esse achado, pois associam essa categoria ao trabalho feminino, já que a mulher possui uma inclinação reconhecida para o cuidado em saúde. Assim como relacionam o elevado número de mulheres na profissão de ACS com achados históricos e o fato de a mulher ser vista, já, desde a idade média, como cuidadora., ${ }^{9,3}$

Em relação ao tempo de serviço foi apresentada a média de 4 anos, estudo de Ferraz e Aerts ${ }^{10}$ aponta que há uma associação entre conhecimento mais elevado dos ACSs sobre TB com tempo de atuação profissional maior ou igual a quatro anos. No entanto, este estudo diverge, já que o tempo de serviço não influenciou a respeito do conhecimento relacionado à busca ativa do SR, pois a maioria dos participantes tinha limitações em definir o que seria a busca ativa.

Já no que se refere à escolaridade, houve uma variação entre ensino médio completo e ensino superior incompleto, sendo que apenas duas pessoas possuíam ensino superior completo. Mota e David ${ }^{9}$ afirmam que quanto maior o grau de escolaridade, mais condições terá o ACS de incorporar novos conhecimentos e orientar as famílias sob sua responsabilidade. Porém, no que tange à busca ativa do SR, o grau de instrução não apresentou uma relevância para uma abordagem diferenciada sobre a temática, podendo ser observada, durante VD que apenas um ACS realizou a abordagem do SR, porém este faz parte do grupo de ensino médio completo.

Assim, pode-se inferir que o foco da VD dos ACSs estava diretamente ligado aos idosos portadores de Doenças Crônicas não Transmissíveis (DCNT), principalmente diabéticos e hipertensos, abordagem que nesse contexto era limitada ao único membro da família, ou seja, os idosos, que recebiam orientações sobre medicamento, dieta e prática de atividade física. Porém, não faziam nenhum tipo de associação desse grupo como vulneráveis à tuberculose, contudo, inúmeros estudos de caso-controle demonstram que o risco de um paciente diabético desenvolver TB varia de 2,44 a 8,33\% comparado com um paciente não diabético, ou seja, a busca ativa do sintomático teria que fazer parte em toda VD desse grupo. ${ }^{11}$

No que concerne à abordagem da busca ativa do SR, durante a VD do ACS, aferimos que não faz parte da rotina dos ACSs estudados, apesar de alguns relatarem, durante a entrevista, que a busca ativa fazia parte da visita domiciliar, porém o observado não corrobora para tais afirmações, pois apenas um ACS realizou abordagem da busca ativa, porém de forma limitada e restrita a um único membro da família.

Outro fator importante a ser debatido é sobre o desvio de função desse trabalhador, pois compromete na qualidade da visita domiciliar, já que se compreende que o papel do ACS, segundo suas competências elaboradas na Política Nacional de Atenção Básica ${ }^{12}$, quer enfatizar seu papel de identificador de problemas, fazendo a ponte entre a comunidade e a ESF e vice e versa, além de educador em saúde, analisando o contexto de vulnerabilidade das famílias, com o intuito de realizar uma VD de qualidade, de acordo com a necessidade de cada indivíduo, família e comunidade.

No entanto, alguns ACSs realizavam atividades que não são de sua responsabilidade, não tendo competência técnica para alguns procedimentos, como aferição da pressão arterial sistêmica e verificação da glicemia capilar. Destaca-se que, no dia da visita, o ACS foi na sua microárea apenas para fazer tais procedimentos. Outro desvio de função comumente observado foi a entrega de consultas especializadas agendadas, em que a visita domiciliar se limita a uma abordagem não ampla da família.

Portanto, diante desse contexto emergiram três categorias, que foram: $\mathrm{O}$ foco da visita domiciliar dos ACSs 
do Município de Belém-PA, Abordagem do ACS na busca ativa do SR e Fatores do processo de trabalho do ACS que refletem na busca ativa do SR.

\section{O foco da vista domiciliar dos ACSs do Município de Belém-PA}

O ACS é um trabalhador que surge de uma experiência nacional no Estado do Ceará, em 1987, atualmente está inserido na ESF, desde julho de 2002 e é uma categoria profissional. Dentre as atribuições previstas na PNAB, cabe ao ACS desenvolver atividades de promoção da saúde, prevenção de doenças e vigilância à saúde, por meio de VD e de ações educativas a serem implementadas junto às famílias acompanhadas. ${ }^{13}$ Assim, cabe a este profissional fazer uma abordagem na família, compreensão que pode ser elucidada com o seguinte depoimento:

"Não isso, não acontece porque a gente ve a familia de um modo geral, olha. Até porque, foi assim que eu cheguei naquele paciente, que relatei para você que teve tuberculose. Eu fui para visitar a mãe dele e daí que cheguei nele, então assim que a gente chega, pois a gente tem uma visão mais ampla e não só um grupo alvo [...]” (E6)

Apesar desse depoimento demonstrar a preocupação do ACS com foco na família, esse foco não foi evidenciado por meio das VD, na qual foi perceptível uma maior atenção voltada para o diabético e hipertenso. Já que essa problemática de DCNT é uma preocupação mundial, Leite et al. ${ }^{14}$ afirmaram que os ACSs têm uma maior preocupação com esse grupo, pelo fato de realizarem cadastros e acompanhamento, incluso no programa Hiperdia. Desse modo, conseguiram obter mais informações sobre essas doenças e também conhecer o número de idosos acometidos pelas mesmas. O depoimento a seguir corrobora com evidências de outros estudos.

"Geralmente como a gente foi acostumada mais sobre os idosos hipertensos e diabéticos, assim o nosso foco são eles, ficando descobertos os outros membros das familias." (E2)

Nota-se, no depoimento de E2, que essa abordagem restrita ao idoso portador de DCNT, não é uma problemática exclusiva do ACS, mas sim da equipe, que ainda apresenta uma abordagem limitada, focada na patologia do usuário. Dessa maneira, é necessário romper a fragmentação na abordagem das doenças, articulando as diversas tecnologias com o recurso pessoal, facilitando o enfrentamento e solução dos problemas que emergem dos usuários, famílias e comunidade, realizando uma aborda- gem integral. No entanto, a abordagem ainda ocorre de forma fragmentada, como demonstra o depoimento:

"são sempre os hipertensos e os diabéticos, são o men grupo primeiro, porque são os que tem maior quantidade, ai eles são os que mais tem frequência de visita, em cima deles por toda a questão do medicamento." (E1)

Assim, essa abordagem fragmentada dos portadores DCNT, que se baseia no uso de medicamento, orientações de atividade físicas e dieta, pautada em orientações para o controle dos níveis pressóricos e glicêmicos. No entanto, esse campo de orientação restrita à patologia não permite que o mesmo faça uma associação desse grupo com a TB, apesar desse grupo ser considerado como vulnerável para a TB, principalmente quando se trata de portadores de diabetes.

O portador de diabetes está sujeito a vários tipos de infecção, principalmente à tuberculose, e a combinação com essa doença tem ocasionado grande aumento de mortes por ano. Mas ainda não se encontrou explicação sobre o fato de a presença do bacilo de Koch, causador da doença, tornar-se tão comum em diabéticos. O problema é crítico, porque ocorre, sobretudo, nos países em desenvolvimento como o Brasil, ou seja, onde há maiores problemas econômicos e, consequentemente, de condições de vida, que propiciam mais tendência a casos de tuberculose. Essa combinação afeta ambos os sexos e pode surgir em qualquer idade, embora a prevalência esteja entre 50 a 59 anos. O risco de diabéticos contraírem tuberculose cresce de três a cinco vezes ${ }^{15}$

Diante dessa associação entre TB e o diabetes, é necessário que haja uma maior preocupação dos ACSs em fazer uma abordagem de busca ativa do SR nesse grupo, de forma que possa ter uma detecção precoce, refletindo em um pronto tratamento, e acompanhamento da ESF com olhar diferenciado, voltado tanto para a condição crônica desse idoso, fazendo um controle glicêmico, como para um tratamento diretamente observado da TB, para que, dessa maneira, se possa ter um impacto na diminuição dos casos de óbitos desse grupo.

\section{Abordagem dos ACS na busca ativa do SR do Muni- cípio de Belém, Pará}

A realização da busca ativa do SR para diagnóstico precoce de casos de TB pulmonar é uma das tarefas a ser realizada pelo ACS na nova proposta de descentralização do PNCT. Apesar dessa atividade ser estabelecida como uma das atribuições dos ACSs, não significa que, de fato, essa ação seja incorporada no seu cotidiano de trabalho. ${ }^{16}$ 
No que concerne à busca ativa do SR, este estudo corrobora para afirmação de que não está incorporado na VD do ACS, uma vez que, durante o acompanhamento de 12 ACSs em 37 VDs, observou-se apenas uma única abordagem sobre a temática. A fala do depoente a seguir enfatiza a observação realizada sobre essa temática.

"Não tenho dificuldade da busca ativa, porém não faz parte da minha visita domiciliar." (E7)

Dessa maneira, espera-se que a busca ativa do SR faça parte da visita domiciliar do ACS, pois é, por meio dela, que serão identificados precocemente aqueles indivíduos que apresentem tosse por três semanas ou mais e encaminhados, assim, para a ESF, a fim de realizar um diagnóstico precoce, culminando para o pronto tratamento, interrompendo a cadeia de transmissão, que é um dos principais objetivos da PCNT.

Contudo, de acordo com o estudo realizado por $\mathrm{Co}-$ riolano et al., ${ }^{17}$ em João Pessoa/PB, foi identificado que não há atividades específicas programadas para a busca ativa realizada nas visitas domiciliares, ficando a identificação dos casos e o planejamento dessas ações nas mãos dos agentes, ou seja, a detecção precoce acaba por depender exclusivamente do ACS.

Porém, há uma limitação no estudo, no que concerne a uma discussão mais ampla sobre o planejamento de ações da equipe de saúde, para busca ativa do SR, já que o estudo não contempla toda a equipe de saúde, mas apenas o ACS. Contudo, inferiu-se, por meio dos discursos desses profissionais, além das observações, que pode haver uma falha no planejamento das ações sobre a temática para a comunidade, podendo ser elucidado com seguinte depoimento:

"Acho, olha, era bom se tivesse assim, não tem a campanba de vacina? Era bom se tivesse essas coisas também para tuberculose para mostrar né, para a população. Porque às vezes a gente chega na casa da pessoa e pergunta: você está com tosse? Ai não perguntamos a quantidade de semana, só falamos que tem que marcar uma consulta, aí isso se perde, porque na maioria das vezes eles nem vem marcar a consulta." (E5)

Já no discurso de E5, que relata sobre a necessidade de campanhas de cunho educativo sobre a TB para a população, ressalta-se a importância de romper o paradigma do modelo, que apenas repassa a informação para o trabalho na lógica da educação em saúde, focando nas vivências proporcionadas ao longo do processo de trabalho, tanto no âmbito da comunidade quanto na ESF, de acordo com a necessidade da população, além de promover uma maior participação social no controle da TB.

Assim, outro aspecto importante para o controle da TB seria o mapeamento da microárea, no qual estariam inclusos todos os grupos vulneráveis para TB, mapeamento que é de responsabilidade da equipe; no entanto, o ACS por ser o facilitador e conhecedor da área, deveria estar trabalhando com essa lógica de atuação. Assim, durante a VD, teria maior possibilidade de identificar o SR. Essa falta de classificação de grupo de vulnerabilidade para TB pode ser evidenciada na fala da depoente:

"Não. Nunca recebi nenbuma informação sobre a questão de grupos vulneráveis para tuberculose." (E6)

Estudo de Teixeira, ${ }^{18}$ realizado nas regiões Sudeste e Nordeste do Brasil, sobre a distribuição de casos de TB, encontrou estreita relação entre ocorrência da doença e áreas de maior vulnerabilidade social com os piores indicadores de qualidade de vida, mostrando que as mazelas sociais estão diretamente ligadas com o aparecimento da doença.

Dessa forma, destaca-se que as condições de moradias observadas no estudo, na maioria das vezes, eram precárias, em média, havia três cômodos de madeira, habitando até 23 pessoas, outro fator agravante era o aglomerado de casas que dificultava a ventilação do ambiente. Essa condição de moradia pode ser observada no discurso:

"a minha área é carente, não muito mais é um pouquinho carente, tem muita casa que tem insalubridade, ambiente fechado, de madeira, não tem ventilação. A única conduta que posso fazer é tentar né... fazer que o vento entre e o sol também né...para iluminar o ambiente ...basicamente isso." (E3)

Percebe-se no discurso que as orientações são sobre a ventilação e iluminação, porém a depoente não faz nenhuma menção à relação da moradia com risco de adquirir TB. Portanto foi possível observar tais ações, durante o acompanhamento das VDs, porém não são seguidas de educação em saúde, pois entende-se que o processo de educação em saúde não se constitui de mera informação, faz-se necessária a explicação da importância de manter o ambiente iluminado e ventilado, para a não proliferação de micro-organismo, como o Mycobacterium tuberculosis.

Assim, salienta-se que as ações voltadas para os determinantes sociais não podem ficar sobre a responsabilidade apenas do ACS, bem como da equipe, mas se fazem necessárias ações intersetoriais, capazes de modificar as condições precárias de moradias, fornecendo, desde sane- 
amento básico até condições de rendas aceitáveis, com o intuito de diminuir o risco dessa população em desenvolver doenças, que estão ligadas às condições socioeconômicas como a TB.

Ainda no que concerne ao grupo de vulnerabilidade, os estudos alertam para alguns hábitos, que precisam ser levados em consideração, durante a classificação de risco para tuberculose, como o abuso de álcool, tabaco, uso de drogas e exposição ocupacional. ${ }^{19}$ Esses hábitos puderam ser observados, com destaque para o uso abusivo de álcool e uso de drogas, em que foi possível verificar que os ACSs reconhecem esses hábitos como fatores de risco para TB, porém não realizam nenhum tipo de abordagem focada nesse grupo, o que pode ser identificado nas falas dos depoentes:

"Como assim? A tá, os usuários de drogas, os alcóolatras, mas eu não faço essa divisão dos grupos prioritários nem para tuberculose e nem para banseníase. Até porque né, na minha área né, tem bastante usuário de drogas, só de boca de fumo tem umas...” (E5)

Compreende-se que abordagem com esse grupo precisa ser diferenciada, e que os ACSs necessitam ser capazes de identificá-lo, porém as ações de saúde direcionadas a esse grupo precisam ser acompanhadas pela equipe multiprofissional, além do envolvimento de outros setores. Portanto, faz-se necessária uma série de articulações intersetoriais com vários setores da sociedade civil, de forma a ampliar as ações dirigidas às populações de difícil acesso, por serem instrumentos essenciais para a promoção de saúde, inclusos como estratégia no controle da TB e controle social. ${ }^{6}$

\section{Fatores do processo de trabalho do ACS que reflete na busca ativa do SR}

A VD é a atividade mais importante do processo de trabalho do ACS. Ao entrar na casa de uma família, ele entra não somente no espaço físico, mas em tudo o que esse espaço representa. Nessa casa, vive uma família, com seus códigos de sobrevivência, suas crenças, sua cultura e sua própria história. Porém, existem fatores do processo de trabalho do ACS, que refletem na qualidade da VD, que precisam ser compreendidos, a fim de melhorar a atuação desse profissional junto ao usuário, família e comunidade, principalmente, quando se trata da temática $\mathrm{TB}$, tema esse que ainda é um tabu durante as visitas domiciliares. ${ }^{20}$

Rosa e Carvalho ${ }^{21}$ relatam que os ACSs podem se deparar com circunstâncias de agravos à saúde da população, que transcendem suas possibilidades de resolu- tividade e mesmo suas atribuições profissionais. Por um lado, entram em contato com diversas vulnerabilidades da população, e, por outro, deparam-se com as questões técnico-administrativas que, geralmente, limitam a efetividade de suas ações, mantendo-os, portanto, numa posição paradoxal. ${ }^{21}$ Nesse contexto paradoxal da função do ACS, o mesmo entra em contato com diversos grupos, além das questões administrativas, representando uma linha trêmula, sujeitando, assim, a desvios de funções que podem comprometer a qualidade da VD.

Deve-se considerar, ainda, que o desvio da função do ACS modifica o modelo assistencial proposto pelas políticas de saúde, uma vez que as práticas de atenção a esse trabalhador, na incumbência de outras tarefas como as atividades burocráticas na unidade de saúde, entrega de consultas especializadas, procedimentos técnicos entre outros podem repercutir de forma negativa em seu fazer profissional. Assim, sobrecarregando-o e diminuindo o tempo disponível para a realização de suas atribuições dentro do serviço. ${ }^{22}$

Por consequência, destaca-se que, neste estudo, foi possível observar os ACSs realizando funções que não são de sua competência, o que prejudica sua atuação diante da comunidade, pois alguns procedimentos, como o de aferição da pressão arterial sistêmica, bem como a glicemia capilar, necessitam de preparo, além de ser um processo de cunho técnico, ou seja, o ACS vem atuando na lógica do modelo tecnicista, em detrimento da educação em saúde, que deveria ser sua principal ação de trabalho.

Compreende-se que essa função, por não fazer parte do plano de atuação desse profissional, pode comprometer a busca ativa do SR, pois se entende que o momento, que poderia ser utilizado para o desenvolvimento de ações voltadas para diversas temáticas, ampliando o campo de aprendizado da comunidade, o mesmo estaria desenvolvendo ações tecnicistas, que não repercutem na troca de saberes. As ações de educação em saúde na VD viabilizam o aumento da participação social, pela troca de saberes e construção de conhecimento, facilitando o controle de agravos negligenciados como a TB.

Ainda no contexto de desvio de função, foi constatado que algumas visitas domiciliares eram apenas para entrega de consultas especializadas e agendamento. Estudo demostra que ações articuladas apenas no âmbito da técnica e da operacionalização de atividades podem levar a um entendimento de que o trabalho dos ACSs se restringe às marcações de consultas ou entregas de recados. De certa forma, essas atividades podem também demonstrar preocupação e cuidado com as singularidades de cada pessoa em situações específicas. No entanto, entregar recados ou marcar consultas de forma mecanizada sem diálogo ou 
interação entre os sujeitos não deve constituir o foco das atividades dos ACSs. ${ }^{23}$

Outras questões que podem ser analisadas são relacionadas aos cadastros e às fichas de acompanhamento, pois é algo apenas quantitativo, em que os ACSs, muitas vezes, não sabem lidar com esses dados, não utilizando a favor da comunidade, principalmente dados sobre a TB. Os ACSs emitiram algumas críticas sobre os cadastros, pois segundo eles, não contemplam a busca ativa do SR, podendo ser elucidado na seguinte fala do depoente.

"O e-sus não veio melhorar a busca ativa do sintomático respiratório, pelo contrário só veio piorar, porque no caso daquela ficha não tem nada sobre tuberculose [...] porque a pergunta é se ele já está com a doença, se ele já teve a doença, não tem os sintomas." ( E3)

Marteleto e David ${ }^{24}$ afirmam que a quantidade de fichas, que são levadas para preencher nas visitações diárias às famílias, destinadas a alimentar o Sistema de Atenção Básica de Saúde (SIAB), pode comprometer o tempo necessário de dedicação ao acolhimento na unidade de saúde e VD, as quais configuram o pilar do trabalho dos agentes: a prevenção e a atenção básica à saúde.

Hoje esse sistema foi substituído pelo E-SUS, justamente para otimizar o tempo relacionado ao trabalho burocrático, no entanto, o mesmo ainda trabalha com a lógica de informações quantitativa. Nesse sentido, destaca-se o depoimento sobre a necessidade de um roteiro de orientação, que possa não servir apenas de forma quantitativa, mas que melhore a qualidade da VD. Como relata o depoente:

"A gente faz uma abordagem muito superficial, olha aqui [...]. Acho que deveria ter sim um roteiro, porque como te falei, a gente acaba sendo acostumada a uma única situação.” (E2)

Assim, essa lógica do processo de trabalho do ACS mecanicista compromete as ações voltadas para comunidade, bem como para uma sobrecarga de trabalho desses profissionais, uma vez que o mesmo exerce funções, que vão além das suas atividades laborais. Isso posto, a reorientação do processo de trabalho perpassa por uma modificação do processo assistencial, que envolve diversos atores sociais, para que possa refletir nas ações calcadas na problematização, tendo uma maior resolutividade dos problemas da comunidade, já que a ampliação do conhecimento do processo saúde-doença impacta na participação social mais efetiva, que é um dos focos para o controle da TB.

\section{CONCLUSÃO}

Este estudo demonstra a relevância da VD com a qualidade do ACS, para uma mudança no contexto do processo saúde-doença, em que é necessária uma abordagem do usuário, familia e comunidade. Todavia, as VDs executadas por esses profissionais são focadas nos idosos portadores de doenças crônicas não transmissíveis nos moldes do modelo tecnicista, limitando, assim, uma abordagem ampla dos diversos determinantes, que circundam a área de abrangência desse profissional, com destaque para a busca ativa do SR, área que apresenta grupos considerados vulneráveis para TB.

Em relação aos grupos de vulnerabilidade para $\mathrm{TB}$, destaca-se a importância da inclusão do mapeamento da área do ACS, no qual possam estar correlacionadas as condições socioeconômica, culturais e os hábitos pessoais (drogadição, etilismo e tabagismo), porém não basta apenas identificação dos pontos críticos da TB, mas se requer um planejamento de ações que possam estar incluindo essa clientela nas práticas desenvolvidas nas ESFs, já que esses ficam à margem do acesso. Assim como a atuação dos ACSs na intensificação da busca do SR nesses grupos poderia acarretar no diagnóstico precoce, proporcionando um tratamento imediato, e impactando na interrupção da cadeia de transmissão da TB.

Sendo assim, a abordagem em relação à busca do SR não faz parte da VD dos ACSs em estudo, pois foi possível verificar que a busca ocorria de forma pontual, sem o acompanhamento da educação em saúde. Logo, para uma mudança desse comportamento é necessário compreender o processo de trabalho desses profissionais, a fim de realizar um diagnóstico dos pontos positivos e negativos, para que, de posse desse diagnóstico, seja possível desenvolver a educação em saúde, nos moldes da problematização, proporcionando um pensamento crítico e reflexivo sobre o seu processo de trabalho.

Dessa forma, os ACSs conseguirão vislumbrar os determinantes sociais que influenciam no controle da TB, e sua importância para o controle dessa patologia, que está intimamente ligada às mazelas sociais, e como esse profissional tem uma representatividade na comunidade pode empoderar a participação social, para que, assim, possa ter um controle mais eficiente.

\section{REFERÊNCIAS}

1. Mendes. As redes de atenção à saúde. Brasília: Organização Pan-Americana da Saúde; 2011.

2. Brasil. Ministério da Saúde. Secretaria de Vigilância em 
Saúde. Departamento de Vigilância Epidemiológica. Manual de Recomendações para o Controle da Tuberculose no Brasil. Brasília; 2011.

3. Maciel ELN, Vieira RCA, Milani EC, Brasil M, Fregona G, Dietze R. O agente comunitário de saúde no controle da tuberculose: conhecimentos e percepções. Cad. Saúde Pública, Rio de Janeiro, 2008; 24(6):1377-1386.

4. Brasil. Ministério da Saúde. Programa Agentes Comunitários de Saúde. PACS. Brasília, DF: Ministério da Saúde; 2001.

5. Taddeo PS, Gomes KWL, Caprara A, Gomes AMA, Oliveira GC, Moreira TMM. Access, educational practice and empowerment of patients with chronic diseases. Ciênc. Saúde Coletiva, Rio de janeiro, 2012 jan./nov.; 17(11):923-2930.

6. Kebian LVA, Acioli S. Visita domiciliar: espaço de práticas de cuidado do enfermeiro e do agente comunitário de saúde. Rev. Enferm. UERJ, Rio de Janeiro, 2011 jul./ set.; 19(3):403-409.

7. Jesus AS, Santos FPA, Rodrigues VP, Nery AA, Machado JC, Couto TA. Atuação do agente comunitário de saúde: conhecimento de usuários. Rev Enferm UERJ. Rio de Janeiro. 2014 mar./abr.; 22(2):239-244.

8. Bardin L. Análise de conteúdo. Trad, Luís Antero Reto, Augusto Pinheiro. 70a ed. São Paulo; 2011.

9. Mota RRA, David HMSL. A crescente escolarização do agente comunitário de saúde: uma introdução do processo de trabalho. Trab. Educ. Saúde [Internet]. 2014 jul./ out. [Citado 2016 dez. 15]; 8(2):229-248, Disponível em: $<$ http://www.scielo.br/pdf/tes/v8n2/a04v8n2.pdf >.

10. Ferraz L, Aerts DRLC. O cotidiano de trabalho do agente comunitário de saúde no PSF em Porto Alegre. Ciênc Saúde Coletiva. 2005 abr./jun.; 10(2):347-55.

11. Rawat J, Sindhwani G, Biswas D. Effect of age on presentation with diabetes: Comparison of nondiabetic patients with new smear-positive pulmonary tuberculosis patients. Lung. 2011; 28(3):187-90.

12 Brasil. Ministério da Saúde. Secretaria de Atenção à Saúde. Departamento de Atenção Básica. Política Nacional de Atenção Básica. Brasília (DF): MS/SAS/DAB; 2012.
13. Lei n. 10.507, de 10 de julho de 2002. Cria a profissão de Agente Comunitário de Saúde e dá outras providências. Brasília; 2002.

14. Leite MT, Dal Pai S, Quintana JM, Costa MC. Doenças crônicas não transmissíveis em idosos: saberes e ações de agentes comunitários de saúde. Rev. Pesqui. Cuid. Fundam. 2015 abr./jun.; 7(2):2263-2276, Disponível em: $<$ http://www.seer.unirio.br/index.php/cuidadofundamental/article/view/3597/pdf_1531>.

15. Fundação Ataulpho de Paiva ( FAP). O grande risco de diabéticos terem tuberculose. FAP [Internet]. 2015 [Citado 2016 dez. 08]. Disponível em: < http://www.fundacaoataulphodepaiva.com.br/blog/o-grande-risco-dediabeticos-terem-tuberculose $/>$.

16. Muniz JN, Palha PF, Monroe AA, Gonzales RC, Ruffino Netto A, Scatena VTC. A incorporação da busca ativa de sintomáticos respiratórios para o controle da tuberculose na prática do agente comunitário de saúde. Ciênc Saúde Coletiva. 2005; 10(2):315-321.

17. Coriolano MWL, Lima MM, Queiroga BAM, RuizMoreno L, Lima LS. Educação permanente com agentes comunitários de saúde: uma proposta de cuidado com crianças asmáticas. Trab. Educ. Saúde [Internet]. 2012 mar./jun. [Citado 2016 dez. 10]; 10(1):37-59. Disponível em: <http://www.scielo.br/pdf/tes/v10n1/v10n1a03. $\operatorname{pdf}>$.

18. Teixeira CF. Promoção e vigilância da saúde no contexto da regionalização da assistência à saúde no SUS. Cad. Saúde Pública. 2002; 18(Suppl):S153-62.

19. Alcântara CCS, Kritski AL, Ferreira VG, Façanha MC, Pontes RS, Mota RS, Leitão TMJS. Fatores associados à tuberculose pulmonar em pacientes que procuraram serviços de saúde de referência para tuberculose. J. Bras. Pneumol. 2012 set./ out.; 38(05).

20. Brasil. Ministério da Saúde. Secretaria de Atenção à Saúde. Departamento de Atenção Básica. O trabalho do agente comunitário de saúde. Brasília; 2009.

21. Rosa AJ, Bonfanti AL, Carvalho CS. O sofrimento psíquico de agentes comunitários de saúde e suas relações com o trabalho. Saúde Soc. 2012; 21(1):141-152.

22. Costa SM, Araújo FF, Martins LV, Nobre LLR, Araújo FM, Rodrigues CAQ. Agente Comunitário de Saúde: ele- 
mento nuclear das ações em saúde. Ciênc. Saúde Coletiva. 2013; 18(07):2147-2156.

23. Sakata KN, Mishima SM. Articulação das ações e interação dos Agentes Comunitários de Saúde na equipe de Saúde da Família. Rev. Esc. Enferm. USP 2012; 46(3):665-72.

24. Marteleto RM, David HMSL. Almanaque do Agente Comunitário de Saúde: uma experiência de produção compartilhada de conhecimentos. Interface (Botucatu) [Internet]. 2014 [Citado 2016 dez. 22]; 18(Suppl.2):1211-1226. Disponível em: <http://www.scielo.br/ pdf/icse/v18s2/1807-5762-icse-18-s2-1211.pdf> .

Submissão: abril de 2017

Aprovação: agosto de 2017 